\title{
The Association of Household Socioeconomic Status and Neighborhood Support System With Adherence to Cardiovascular Fitness Among Persons With Diabetes Mellitus in Ghana a Hospital-based Cross Sectional Study.
}

Be-lkuu Doglikuu ( $\sim$ doglikuudo@gmail.com )

Tehran University of Medical Sciences https://orcid.org/0000-0001-5592-193X

Abdulai Abubakari

University for Development Studies

Mehdi Yaseri

Tehran University of Medical Sciences

Elham Shakibazadeh

Tehran University of Medical Sciences

Abolghassem Djazayery

Tehran University of Medical Sciences

Khadijeh Mirzaei

Tehran University of Medical Sciences

Original investigation

Keywords: Diabetes mellitus, Social/neighborhood supports, Adherence, Physical activity, Ghana

Posted Date: August 12th, 2021

DOI: https://doi.org/10.21203/rs.3.rs-777088/v1

License: (9) This work is licensed under a Creative Commons Attribution 4.0 International License. Read Full License 


\section{Abstract}

Background: Diabetes mellitus (DM) is an independent risk-factor for cardiovascular diseases. Physical activities (PAs) could reverse this risk factor. However some factors could influence adherence to PAs. Our study investigates the association of household socioeconomic status and neighborhood support system with adherence to cardiovascular fitness among persons with diabetes mellitus (DM) in Ghana.

Methods: Facility-based cross-sectional-study was conducted among 530 T2DM patients in Ghana. Structured-questionnaires were used to collect demographic, anthropometric, and clinical variables. Household socioeconomic status (SES) was assessed using wealth-composite index and adherence to PAs measured using WHO PA-short form questionnaires. SPSS version-22 was used in data analysis.

Results: There were significant mean difference in low $(P=0.010)$ and high $(P=0.0001)$ social/neighborhood supports according to place of residence. After adjusting for age and diabetes duration, high SES (quintile 3) Adjusted Odd Ratio (AOR) $=0.68,95 \%$ confidence interval $(95 \% \mathrm{Cl})(0.22,0.07)$, moderate SES (quintile 3$), \mathrm{AOR}=3.16,95 \% \mathrm{Cl}(1.01,9.89)$ and high social support system (quintile 2) $\mathrm{AOR}=3.29,95 \% \mathrm{Cl}(1.02,10.58)$ were significant for adherence to cardiovascular fitness. Furthermore Low SES (quintile 3) $A O R=3.52,95 \% \mathrm{Cl}(1.44,8.59)$ and low social support system (quintile 1) $A O R=1.05,95 \% \mathrm{Cl}(1.05,1.09)$ were significant for adherence to sedentary lifestyle among persons with diabetes mellitus.

Conclusion: SES, and Social/neighborhood support systems are associated with adherence to cardiovascular fitness. Health care workers should prioritized these variables as modifiable factors in diseases preventions and health promotion

\section{Introduction}

Physical activity (PA) also known as cardiovascular fitness is any bodily movement produced by skeletal muscles that result in energy expenditure beyond resting level[1]. This broad definition of the physical activity involves virtually all types of activity like walking, cycling, dancing, traditional games, gardening, housework, sports and other activities. Recommendations of PA to individuals may vary depending on the individuals' characteristics and health status. Technically, an individual is said to be physically inactive when there is no marked increase in energy expenditure above resting level[2]. Physically inactivity or sedentary lifestyle is a kind of lifestyle that involves a lot of sitting and lying down, with very little exercise. Although sedentary lifestyle does not means a person is completely inactive, usually the activities they perform are not enough to gain health benefits. Physical activity can be classified into two main categories: 'Physical activity that involves planned coordinated and repetitive bodily movements', i.e. jogging, swimming, cycling etc., and 'physical activity that involve unplanned coordinated bodily movement', i.e. standing, commuting to and from school or work, or participating in household chores or occupational work[3].The adoption and maintenance of PAs are critical foci for healthy living and management of blood glucose in persons with diabetes and pre-diabetes. Studies show that exercise independently improves blood glucose in type 2 diabetes, reduces cardiovascular risk factors, contributes to weight loss, and improves the general well-being of individuals[4]. It is also proven that regular exercise may prevent or delay the onset and development of type 2 diabetes[5] and also contributes significantly to health benefits of persons with type 1 diabetes (e.g., improved cardiovascular fitness, improved insulin sensitivity, and strengthen muscle tone) [6]. The two main categories of PA or cardiovascular fitness discussed above can be recommended to individuals for health benefits. However, recommendations should be tailored to meet the specific needs of each individual. It is known that planned coordinated and repetitive PA also known as aerobic exercise training is an effective intervention in preventing and treating insulin resistance and type 2 diabetes. However, several important issues regarding the effects of exercise on insulin action, and obesity remain unclear[7, 8]. Despite this, the American Diabetes Association (ADA) and the WHO recommend that people get at least 150 minutes of moderate to vigorous intensity aerobic PA per week for healthy living[9]. WHO further develop new guidelines for PA to address children, adolescents, adults, older adults and people living with special condition such chronic diseases, pregnancy, postpartum or disability[10]. In this new guideline, WHO recommends that all adults undertake 150-300 min of moderate-intensity, or 75-150 min of vigorous-intensity physical activity, or some equivalent combination of moderate-intensity and vigorous-intensity aerobic physical activity per week. Among children and adolescents, the guideline recommends that an average of $60 \mathrm{~min} /$ day of moderate-to-vigorous intensity aerobic physical activity across the week should be performed to provide health benefits. For pregnant and postpartum women, WHO new guideline recommends regular strength training exercise for them. For all age groups and people with chronic conditions and Loading [MathJax]/jax/output/CommonHTML/jax.js egular muscle-strengthening activity for everyone, and advice against sedentary 
behaviours. Although convergence lines of evidences have supported the effects of PA, and recommends it for health, individuals and population characteristics such socioeconomic status (SES) and social support network could influence adherence to PA. For instance, it is reported that increasing social support systems encouraged individuals adopt to healthier behaviours such as reducing unhealthy dietary fat intakes, participate in physical activities, or give up smoking which are risk factors for disease onset and progress[11]. In other development, people's desire to participate in PA was influenced by accessibility to resources that support PA[12]. In a community study about income status and PA, positive correlations was reported between level of physical activity and income status of male and female working-class[13]. Highest physical activity levels were noted among respondents who reported steady income status, and those with highest income and savings with no debts [13]. Although SES and social support system have shown to influence adherence to PA in some part of the world, little to no such evidence exists in Ghana. Ghana's population is heterogeneous with diverse social classes and income statuses. Yet little studies have been conducted to highlight the influences of these variables on health outcomes. In line with this preliminary observation, our study therefore seeks to assess the association of household socioeconomic status, and neighbourhood support system with adherence to cardiovascular fitness among persons with diabetes mellitus in Ghana.

\section{Methods}

The aim of our study is to investigate how household socioeconomic status and neighbourhood support system are associated with adherence to cardiovascular fitness among persons with diabetes mellitus in Ghana. To achieve this, hospital based cross-sectional survey was conducted among 530 persons living with DM in Brong Ahafo Region (BAR), Ghana. Single population proportion

formula $\left(n=\frac{Z^{2} \mathrm{P}(1-\mathrm{P})}{e^{2}}\right)$ was used to estimate sample size of the study. The letter ' $n$ ' in the formula denotes study sample size, ' $\mathrm{Z}$ ' denotes normal standard distribution of 1.96 for $95 \%$ confidence interval, ' $P$ ' is the true population proportion of adherence to therapy recommendation among persons with diabetes mellitus in the study area (Brong Ahafo region) and 'e' is standard error (5\%). Previous study in Brong Ahafo region Ghana, reported that prevalence of adherence to therapy recommendation in general among persons with DM was 68.5\% [14]. Substituting these values in the equation, the sample size $n$ was calculated as

$n=\frac{1.96^{2 *} 0.685(1-0.685)}{0.05^{2}}=332$. However, for the fear of non-response on participants' part and registration error by data collectors, a contingency sample of $60 \%$ was added to the estimated sample. The final sample was therefore increased to $0.6 * 332=531.2 \approx 532$.

\section{Sampling}

Simple random sampling was used to select 6 hospitals, and the eligible participants consecutively recruited using systematic random sampling. Individuals aged 18 years and above diagnosed with T2DM by physicians using the American diabetes association (ADA) diagnostic and classification guideline 2011[15] were recruited. We excluded the frailly sick, participants' who are, intellectually deficient and cannot answer interview questions, and pregnant and lactating mothers diagnosed with DM were also excluded. We excluded pregnant and lactating who were diagnosed with DM from our study because this group were considered high risk group because of the double burden they carry (diabetes and pregnancy or lactation). 
Table 1

Participant general characteristics and demographic variable

\begin{tabular}{|c|c|c|}
\hline Variable & Means(SD) & Number (\%) \\
\hline Age(years) & $58.10(9.70)$ & \\
\hline Wight(Kg) & 61.70(9.30) & \\
\hline $\mathrm{BMI}\left(\mathrm{Kg} / \mathrm{m}^{2}\right)$ & $23.14(2.92)$ & \\
\hline HDL-cholesterol & $1.74(0.90)$ & \\
\hline LDL-cholesterol & $5.15(3.42)$ & \\
\hline Triglycerides & $4.64(14.14)$ & \\
\hline Systolic (BP)mmHg & 135.67(7.79) & \\
\hline Diastolic (BP)mmHg & 77.79(12.79) & \\
\hline Duration lived with diabetes(years) & $4.90(5.40)$ & \\
\hline \multicolumn{3}{|l|}{ Sex } \\
\hline Male & & $154(29.1)$ \\
\hline Female & & $376(70.9)$ \\
\hline \multicolumn{3}{|l|}{ Marital Status } \\
\hline Married & & $340(64.2)$ \\
\hline Single & & $20(3.8)$ \\
\hline Widow & & $107(20.2)$ \\
\hline Divorce & & 63(11.9) \\
\hline \multicolumn{3}{|l|}{ Place of Residence } \\
\hline Village & & $39(7.4)$ \\
\hline Town & & $404(76.2)$ \\
\hline City & & $87(16.4)$ \\
\hline \multicolumn{3}{|l|}{ Educational Level } \\
\hline No education & & 202(38.1) \\
\hline Primary & & $85(16.0)$ \\
\hline Junior High & & 132(24.9) \\
\hline Senior High & & $67(12.6)$ \\
\hline Training College & & $21(4.0)$ \\
\hline Polytechnic & & $10(1.9)$ \\
\hline University & & $13(2.5)$ \\
\hline
\end{tabular}


Table 2

Comparison of participants' mean demographic characteristics, biochemical parameters, social support and socioeconomic status with place of residence

\begin{tabular}{|c|c|c|c|c|c|c|c|c|}
\hline \multicolumn{9}{|c|}{ Place of residence } \\
\hline \multirow[t]{2}{*}{ Variable } & \multicolumn{2}{|c|}{ Village } & \multicolumn{2}{|c|}{ Town } & \multicolumn{4}{|c|}{ City } \\
\hline & $\mathrm{n}$ & Mean (SD) & $n$ & Mean (SD) & $\mathrm{n}$ & Mean (SD) & $\begin{array}{l}\text { F- } \\
\text { statistics } \\
\left(\mathrm{df}_{1}\right. \\
\left.\mathrm{df}_{2}\right)^{\mathrm{a}}\end{array}$ & $\begin{array}{l}\text { P- } \\
\text { value }\end{array}$ \\
\hline \multirow[t]{2}{*}{ Age(years) } & 39 & $59.36(9.45)$ & 404 & $57.92(9.72)$ & 87 & $58.10(9.46)$ & 0.39 & 0.672 \\
\hline & & & & & & & $(0.60)$ & \\
\hline \multirow{2}{*}{$\begin{array}{l}\text { Fasting blood } \\
\text { sugar } \\
(\mathrm{mmol} / \mathrm{L})\end{array}$} & 39 & $10.49(5.46)$ & 404 & $9.92(4.35)$ & 87 & $10.45(5.01)$ & 0.69 & 0.501 \\
\hline & & & & & & & $(1.26)$ & \\
\hline \multirow{2}{*}{$\begin{array}{l}\text { Total- } \\
\text { cholesterol } \\
\text { (mmol/L) }\end{array}$} & 39 & $7.34(3.87)$ & 404 & $7.25(3.44)$ & 87 & $6.82(3.57)$ & 0.59 & 0.556 \\
\hline & & & & & & & $(0.21)$ & \\
\hline \multirow{2}{*}{$\begin{array}{l}\text { Receive low } \\
\text { social support }\end{array}$} & 39 & $0.43(0.88)$ & 372 & $-0.010(0.96)$ & 85 & $-0.15(1.16)$ & 4.65 & 0.010 \\
\hline & & & & & & & $(1.84)$ & \\
\hline \multirow{2}{*}{$\begin{array}{l}\text { Receive } \\
\text { moderate } \\
\text { social support }\end{array}$} & 39 & $-0.26(0.67)$ & 372 & $0.017(0.98)$ & 85 & $0.05(1.21)$ & 1.47 & 0.232 \\
\hline & & & & & & & $(1.27)$ & \\
\hline \multirow{2}{*}{$\begin{array}{l}\text { Receive high } \\
\text { social support }\end{array}$} & 39 & $-0.01(0.64)$ & 372 & $0.01(1.03)$ & 85 & $-0.03(0.99)$ & 0.05 & 0.954 \\
\hline & & & & & & & $(0.07)$ & \\
\hline \multirow{2}{*}{$\begin{array}{l}\text { High } \\
\text { socioeconomic }\end{array}$} & 22 & $-0.89(0.72)$ & 200 & $0.02(0.99)$ & 41 & $0.36(0.89)$ & 11.48 & 0.0001 \\
\hline & & & & & & & $(3.63)$ & \\
\hline \multirow{2}{*}{$\begin{array}{l}\text { Moderate } \\
\text { socioeconomic }\end{array}$} & 22 & $-0.06(0.33$ & 200 & $0.04(1.09)$ & 41 & $-0.16(0.72)$ & 0.68 & 0.507 \\
\hline & & & & & & & $(0.96)$ & \\
\hline \multirow{2}{*}{$\begin{array}{l}\text { Low } \\
\text { socioeconomic }\end{array}$} & 22 & $0.82(0.54)$ & 200 & $0.79(0.59)$ & 41 & $0.60(1.62)$ & 0.67 & 0.378 \\
\hline & & & & & & & $(0.31)$ & \\
\hline \multirow{2}{*}{$\begin{array}{l}\text { Cardiovascular } \\
\text { fitness (PA) }\end{array}$} & 39 & 3353.33(4415.20) & 404 & $2896.55(4029.15)$ & 87 & $2366.55(3351.97)$ & 1.412 & 0.204 \\
\hline & & & & & & & $(0.41)$ & \\
\hline
\end{tabular}


Table 3

Association of socioeconomic status, neighbourhood support system with adherence to cardiovascular fitness

\begin{tabular}{|c|c|c|c|c|c|c|c|c|c|}
\hline Variables & Ref & $\begin{array}{l}\text { Moderate } \\
\text { CAV Fitness } \\
\text { Crude. } \\
\text { OR }(95 \% \mathrm{Cl})\end{array}$ & $\begin{array}{l}\mathrm{P} \text { - } \\
\text { value }\end{array}$ & $\begin{array}{l}\text { Sedentary } \\
\text { CAV Fitness } \\
\text { Crude. } \\
\text { OR }(95 \% \mathrm{Cl})\end{array}$ & $\begin{array}{l}\mathrm{P}- \\
\text { value }\end{array}$ & $\begin{array}{l}\text { Moderate } \\
\text { CAV Fitness } \\
\text { Adj. OR } \\
(95 \% \mathrm{Cl})\end{array}$ & $\begin{array}{l}\mathrm{P}- \\
\text { value }\end{array}$ & $\begin{array}{l}\text { Sedentary } \\
\text { CAV Fitness } \\
\text { Adj. OR } \\
(95 \% \mathrm{Cl})\end{array}$ & $\begin{array}{l}\mathrm{P} \text { - } \\
\text { value }\end{array}$ \\
\hline $\begin{array}{l}\text { High } \\
\text { Socioeconomic3 }\end{array}$ & Ref & 1 & & 1 & & 1 & & 1 & \\
\hline $\begin{array}{l}\text { High } \\
\text { Socioeconomic } 2\end{array}$ & & $\begin{array}{l}0.29(0.10 \\
0.86)\end{array}$ & 0.03 & $\begin{array}{l}0.43(0.19 \\
0.98)\end{array}$ & 0.05 & $\begin{array}{l}0.68(0.22, \\
0.07)\end{array}$ & 0.01 & $\begin{array}{l}0.41(0.17 \\
0.98)\end{array}$ & 0.04 \\
\hline $\begin{array}{l}\text { High } \\
\text { Socioeconomic } 1\end{array}$ & & $\begin{array}{l}0.82(.291 \\
2.32)\end{array}$ & 0.71 & $\begin{array}{l}1.59(0.66 \\
3.84)\end{array}$ & 0.31 & $\begin{array}{l}0.29(0.07 \\
0.97)\end{array}$ & .044 & $\begin{array}{l}1.30(0.51 \\
3.35)\end{array}$ & 0.58 \\
\hline $\begin{array}{l}\text { Moderate } \\
\text { Socioeconomic3 }\end{array}$ & Ref & 1 & & 1 & & 1 & & 1 & \\
\hline $\begin{array}{l}\text { Moderate } \\
\text { Socioeconomic } 2\end{array}$ & & $\begin{array}{l}1.05(0.36 \\
3.03)\end{array}$ & 0.94 & $\begin{array}{l}0.75(.341 \\
1.63)\end{array}$ & 0.46 & $\begin{array}{l}3.16(1.01, \\
9.89)\end{array}$ & 0.05 & $\begin{array}{l}0.88(0.36 \\
2.16)\end{array}$ & 0.78 \\
\hline $\begin{array}{l}\text { Moderate } \\
\text { Socioeconomic } 1\end{array}$ & & $\begin{array}{l}3.22(1.13, \\
9.16)\end{array}$ & 0.03 & $\begin{array}{l}0.96(0.42, \\
2.20)\end{array}$ & 0.92 & $\begin{array}{l}1.18(0.40 \\
3.49)\end{array}$ & 0.76 & $\begin{array}{l}0.80(0.36 \\
1.81)\end{array}$ & 0.59 \\
\hline $\begin{array}{l}\text { Low } \\
\text { Socioeconomic } 3\end{array}$ & Ref & 1 & & 1 & & 1 & & 1 & \\
\hline $\begin{array}{l}\text { Low } \\
\text { Socioeconomic } 2\end{array}$ & & $\begin{array}{l}1.09(0.38 \\
3.12)\end{array}$ & 0.88 & $\begin{array}{l}3.62(1.52, \\
8.62)\end{array}$ & 0.004 & $\begin{array}{l}0.91(0.30 \\
2.72)\end{array}$ & 0.86 & $\begin{array}{l}3.52(1.44 \\
8.59)\end{array}$ & 0.001 \\
\hline $\begin{array}{l}\text { Low } \\
\text { Socioeconomic } 1\end{array}$ & & $\begin{array}{l}1.72(0.58 \\
5.05)\end{array}$ & 0.32 & $\begin{array}{l}3.68(1.37, \\
9.91)\end{array}$ & 0.010 & $\begin{array}{l}1.36(0.44, \\
4.16)\end{array}$ & 0.59 & $\begin{array}{l}3.35(1.21 \\
9.29)\end{array}$ & 0.020 \\
\hline $\begin{array}{l}\text { High Social } \\
\text { Support } 3\end{array}$ & Ref & 1 & & 1 & & 1 & & 1 & \\
\hline $\begin{array}{l}\text { High Social } \\
\text { Support } 2\end{array}$ & & $\begin{array}{l}2.76(0.91 \\
8.38)\end{array}$ & 0.07 & $1.01(0.44,2.35)$ & 0.98 & $\begin{array}{l}3.29(1.02, \\
10.58)\end{array}$ & 0.05 & $\begin{array}{l}0.98(0.41 \\
2.34)\end{array}$ & 0.96 \\
\hline $\begin{array}{l}\text { High Social } \\
\text { Support } 1\end{array}$ & & $\begin{array}{l}1.79(0.62 \\
5.18)\end{array}$ & 0.28 & $0.77(0.35,1.69)$ & 0.51 & $\begin{array}{l}2.11(0.69 \\
6.39)^{0}\end{array}$ & 0.18 & $\begin{array}{l}0.81(0.36 \\
1.82)\end{array}$ & 0.60 \\
\hline $\begin{array}{l}\text { Moderate Social } \\
\text { Support } 3\end{array}$ & Ref & 1 & & 1 & & 1 & & 1 & \\
\hline $\begin{array}{l}\text { Moderate Social } \\
\text { Support } 2\end{array}$ & & $\begin{array}{l}1.49(0.44 \\
4.99)\end{array}$ & 0.52 & $\begin{array}{l}1.03(0.41 \\
2.61)\end{array}$ & 0.94 & $\begin{array}{l}1.52(0.44 \\
5.28)^{0}\end{array}$ & 0.51 & $\begin{array}{l}1.17(0.45 \\
3.06)\end{array}$ & 0.75 \\
\hline $\begin{array}{l}\text { Moderate Social } \\
\text { Support } 1\end{array}$ & & $\begin{array}{l}0.96(0.28 \\
3.32)\end{array}$ & 0.95 & )$^{0.81(0.33,1.98}$ & 0.64 & $\begin{array}{l}1.06(0.29 \\
3.78)\end{array}$ & 0.93 & $\begin{array}{l}0.86 \\
(0.34,2.18)\end{array}$ & 0.75 \\
\hline $\begin{array}{l}\text { Low Social } \\
\text { Support } 3\end{array}$ & Ref & 1 & & 1 & & 1 & & 1 & \\
\hline $\begin{array}{l}\text { Low Social } \\
\text { Support } 2\end{array}$ & & $\begin{array}{l}1.23(.46 \\
3.31)\end{array}$ & 0.68 & $1.17(0.5,2.64)$ & 0.71 & $\begin{array}{l}1.11(0.39 \\
3.08)\end{array}$ & 0.85 & )$^{1.05(0.45,2.44}$ & 0.93 \\
\hline $\begin{array}{l}\text { Low Social } \\
\text { Support } 1\end{array}$ & & $\begin{array}{l}1.58(0.54 \\
4.69)\end{array}$ & 0.41 & $\begin{array}{l}1.61(0.70 \\
3.68)\end{array}$ & 0.26 & $\begin{array}{l}1.53(0.51, \\
4.61)\end{array}$ & 0.45 & $\begin{array}{l}1.05(1.05, \\
1.09)\end{array}$ & 0.006 \\
\hline
\end{tabular}

\section{Ethical approval}

Ghana Health Service Ethics Review Committee (GHS-ERC008/08/18) and Tehran University of Medical Sciences Ethics Review board (IR.TUMS.VCR.REC.1397.409) approved the study protocol. Each participant in the study was asked to sign an informed consent form before participatina. This research project was performed in accordance with the Declaration of Helsinki.

Loading [MathJax]/jax/output/CommonHTML/jax.js 
Age, diabetes-duration, medications intakes and other demographic characteristics were assessed using structured questionnaires. Adult weighing scale and stadiometer were used to measure weight and height and recorded to the nearest $0.5 \mathrm{~kg}$ and $0.5 \mathrm{~m}$ respectively. These measurements were taken when participants were in light clothes without shoes, and were in standing position. Body mass index (BMI, kg/m2) was calculated by dividing weight in kilograms with height in square meters. Systolic and diastolic blood pressures were measured using manual sphygmomanometer and stethoscope, and the reading recorded to the nearest $0.5 \mathrm{mmHg}$ after participants were allowed to relax for 5 or more minutes.

\section{Assessing socioeconomic status}

Socioeconomic status was assessed using composite wealth index. We used this proxy indicator because participants were unwilling to tell much household income they earn through sales and salaries per month. Using this method, we asked participants to name items and properties they possess including fixed assets such as land and building, and movable assets such as vehicles. Principal component analysis (PCA) to extract participants' socioeconomic status from the wealth index. The extracted socioeconomic status was categorized into three quintiles: - poorest, middle and richest quintiles to represent participants' SES. After the extraction, the percentage of total variance explained by the three factors was $35.6 \%$

\section{Neighbourhood support system}

Neighbourhood or social support was assessed using structured questionnaire. Participants were asked to self-report on a continue scale, how frequent they received support in the form of materials gifts, cash, in kind or volunteerism from friends, relatives, love ones, or from religious organizations like churches, mosques, or from cooperate institutions in their societies. Participants who reported "very frequently" were classified to have high social support, those who reported "frequently" were said to have moderate social support, and those who reported "less frequently" were said to have low social support system.

\section{Assessing physical activity levels}

WHO recommendations on physical activity for health was used to analyse PA of Participants. In estimating the physical activity level of participants, the total time spent in doing the physical activity during a typical week and the intensity of the physical activity were taken into account. WHO recommends that adults should do at least 150 minutes of moderate-intensity physical activity OR 75 minutes of vigorous-intensity physical activity $\mathrm{OR}$ an equivalent combination of moderate and vigorous-intensity physical activity achieving at least 600 MET-minutes. In work related physical activity, participants who reported moderate work PA were given Moderate MET value $=4.0$; those who reported vigorous work PA were give Vigorous MET value $=8.0$. In transport physical activity, participants who reported Cycling and walking were given MET value $=4.0$. Furthermore participants who engaged in recreational physical activities were given Moderate MET value $=4.0$ if they reported moderate recreational PA, and high MET value $=8.0$ if they reported vigorous recreational PA. The MET values of each PA level was multiply with the number of hours and days spent doing the particular type of PA. The results obtained from participants were grouped with reference to the WHO PA cut of points (Not meet recommendations if Total Physical Activity MET minutes per week are <600) and (Meet recommendation if Total Physical Activity MET minutes per week are 2600)[16]. But to categorise PA into 3 levels for analysis, in our study we used the WHO 3 levels categorization of PA, thus high PA, moderate PA and Sedentary lifestyle. According to the 3 levels categorization, participants are said to be living sedentary life if their Total Physical Activity MET minutes per week is $<600$. Those who have Total Physical Activity MET minutes per week 600 to 800 are said to have moderate PA, and those who have Total Physical Activity MET minutes per week $\geq 900$ are said to be highly physically active.

\section{Results}

Participants' general and demographic characteristics are presented in Table 1. Mean (SD) of Age, Wight and BMI are 58.10(9.70), $6.70(9.30)$ and $23.14(2.92)$ respectively. About $80 \%$ of the participants are females; married (64.2\%); and live in small towns and villages $(76.2 \%)$. More than $38 \%$ of participants have no formal education; $1.9 \%$ has education up to polytechnic; $2.5 \%$ have it up to

Loading [MathJax]/jax/output/CommonHTML/jax.js 
university and the rest have other forms of education. There were significant mean difference in receiving social supports according to place of residence. Receiving low social supports $(P=0.010)$ and receive high social support $(P=0.0001)$, table 2 .

The association of socioeconomic status and neighbourhood support system with adherence to cardiovascular fitness are presented in table 3. After adjusting for age and diabetes duration, high SES (quintile 3) Adjusted Odd Ratio (AOR) $=0.68,95 \%$ confidence interval $(95 \% \mathrm{Cl})(0.22,0.07)$ was significant for adherence to moderate cardiovascular fitness, moderate SES (quintile 3$), A O R=3.16$, $95 \% \mathrm{Cl}(1.01,9.89)$ was significant for adherence to moderate cardiovascular fitness while low SES (quintile 3 ) $\mathrm{AOR}=3.52,95 \% \mathrm{Cl}$ $(1.44,8.59)$ was significant for adherence to sedentary lifestyle. Furthermore, high social support system (quintile 2) AOR =3.29, $95 \% \mathrm{Cl}(1.02,10.58)$ was significant for adherence to moderate cardiovascular fitness whereas low social support system (quintile 1) AOR $=1.05,95 \% \mathrm{Cl}(1.05,1.09)$ was significant for adherence to sedentary lifestyle among persons with diabetes mellitus.

\section{Discussion}

Physical activity is a major factor in self-care approaches to controlling DM and its related complications[17]. According to Bandura's social theory, factors such as social support systems are effective in adherence of behaviour[18]. Socioeconomic status has also been shown to be associated with adherence to behaviour[19]. Based on these premises, we aimed to determine whether neighbourhood support systems were significantly difference according to participants' places of residence, and also to determine whether SES and neighbourhood support system could be associated with adherence to cardiovascular fitness/PA among persons with DM in Ghana.

At the end of the study we found that there were significant mean difference in receiving low and high social/neighbourhood supports according to participants' places of residence. We also found that high SES (quintile 3) and moderate SES (quintile 3) were associated with adherence to moderate cardiovascular fitness/PA, while low SES (quintile 3) was associated with sedentary behaviours. Furthermore, we noticed that high social neighbourhood supports (quintile 2) was associated with adherence to moderate cardiovascular fitness/PA and low social/neighbourhood support system (quintile 1) was associated with adherence to sedentary behaviours.

Socioeconomic status refers to individuals' social position relative to others in a society. Socioeconomic status is known to be a strong determinant of overall survival of human beings but many health care providers and policy makers pay less attention to this. It is reported that people of low socioeconomic status are more likely to have poorer health outcomes, and shorter life expectancy than people of higher socioeconomic status[20,21] , and this could be attributed partly to lower prevalence of PA[22] among this persons. It is also reported elsewhere that low SES is associated with large increased in cardiovascular disease (CVD) risk in men and women[23]. These observations could be interpreted in two ways. Firstly, people on low socioeconomic quintile or class (low SES) may lack knowledge and information about existing health promotion strategies they can take advantage of to promote their health. Secondly, they may lack the ability to purchase and consume health promoting foods and other products that could directly improve their health (CVD risk). In a Meta-Ethnographic approach to understanding socioecological complexities in participating in PA, it was observed that participation in PA was influenced by accessibility to resources that support PA[12]. These finding are consistent with our finding. In our study we noticed that high and moderate socioeconomic statuses were associated with adherence to moderate PA while low SES was associated with adherence with sedentary behaviour. In the Meta-Ethnographic approach to understanding socioecological complexities in participating in PA, people were desired to travel to parks, public sports centres, or local private health clubs to pursue PA but lack access to reliable transportation such as private cars, public transport, and bicycle infrastructure[12] militated against their desires.

In other development, PA level was found correlated with increasing SES[24]. It is reported that adopting moderate to vigorous physical activity by individuals lowers risk of cancer other chronic diseases[25]. Physical activity is also shown to be safe and helpful to most people before, during, and after cancer treatment, and can improve the quality of life as well, and give the needed energy to help the individuals cope with the side effects of treatment and possibly decrease the risk of new cancers in the future[26]. Indeed PA is the magic bullet providing direct benefits to people living with chronic non-communicable diseases and giving protective effects to the entire population in general. However, population, individuals and environmental factors make adoption and adherence to PA quit problematic, thus causing many people to have low adherence to PA. For instance, across countries, studies show that children' outdoor PAs are associated with features of the environment, including walking-related features, and physical

Loading [MathJax]/jax/output/CommonHTML/jax.js 
activity resources $[27,28]$. Environmental safety has been reported to influence PA among children with and without Autism Spectrum Disorder, with significant association found between feeling safe and engaging in PA among children [29].

Apart from the build in environment in neighbourhood that can influence PA, other factors such supports from the neighbourhood can also influence PA[30, 31]. These finding are consistent with our findings. In our study we realized that high social/neighbourhood support system increase the odds of participating in PA whereas low social/neighbourhood support system decreased the odds. These results could be true because neighbourhood cohesion and social capital are shown to be good predictors for adherence to health promoting behaviours.

In a study among school children, it is reported that favourable social environment was positively associated with physical activity[32], thus re-affirming the importance of social support on incidence and adherence of PA. In a different development among persons with DM, participation in community organizations was shown to be associated with more physical activity $(O R=1.53)[33]$, also affirming the impact of neighbourhood support on the adherence to PA.

Other studies have also reported on the impact of social/neighbourhood support on adherence to other treatment regimens in general among persons with chronic non-communicable diseases [34-36], which supported our finding. Although significant results were found in our study, we cannot conclude that significant associations exist in household socioeconomic status and neighbourhood support system for adherence to cardiovascular fitness/PA among persons with DM in Ghana. This is because our study suffers some biases, limitations and methodological flaws.

\section{Limitations}

Our study employed facility based cross sectional study to investigate the associations between the study variables. Since cross sectional study cannot detect causal associations of study variables, we cannot conclude based on our results, and therefore suggest that subsequent studies should consider adopting stronger study design like longitudinal cohort study or clinical trial to investigate this matter. Other limitation is that we recruited relatively small sample size (530) which limits the power of our study; in this regard we again recommend that subsequent studies should consider larger sample size to improve the power of the study.

Despite these biases, limitations and methodological flaws, the strength of our study is that it has contributed knowledge in literature by exploring the association of household socioeconomic status and neighbourhood support system for adherence to cardiovascular fitness/PA among persons with DM in Ghana. This will contributes knowledge in the care of persons with DM in Ghana and other part of the world.

\section{Conclusion}

In this study we found that there were significant mean difference in receiving low and high social/neighbourhood supports according to participants' places of residence. We also found that high SES (quintile 3) and moderate SES (quintile 3) were associated with adherence to moderate cardiovascular fitness/PA, while low SES (quintile 3) was associated with sedentary behaviours. We noticed that high social/neighbourhood supports (quintile 2) was associated with adherence to moderate cardiovascular fitness/PA and low social/neighbourhood support system (quintile 1) was associated with adherence to sedentary behaviours. These results therefore caution health care professionals to consider social/neighborhood support system and SES as modifiable factors in disease preventions and health promotion.

\section{Declarations}

\section{Ethical Approval}

Ghana Health Service Ethics Review Committee and Tehran University of Medical Sciences Ethics Review board granted the approval for this study. All participants were also requested to sign an informed consent form before participating in the study.

\section{Consent for publication}

Not applicable

Loading [MathJax]/jax/output/CommonHTML/jax.js 
Availability of data and materials

Data and materials for this study are with the corresponding author, and will be made available upon request

\section{Competing interest}

All authors declared no conflict of interest in this study.

\section{Funding}

This study was funded by Tehran University of Medical Sciences.

\section{Authors' contributions}

\section{Acknowledgment}

We acknowledge the regional director of health services in Brong Ahafo region, all the medical superintendents' nurses, nutritionists, dieticians, and all the laboratory scientists who helped us in our data collection process. We also acknowledge all the participants who took part in this study.

\section{Authors' contribution}

BDD collected data, analysed and wrote the manuscript for the publication. AA obtained ethical clearance in Ghana, supervised data collection, and proofread the final version of the manuscript. YM supervised the data analysis and proofread the final version of the manuscript. SE proofread the final version of the manuscript. AD acquired funding for the study, supervised the data collection, and proofread the final version of the manuscript before publication. MK supervised, coordinated the study, and took part in the data collection, data analysis and wring up the manuscript.

\section{References}

1. Shioya T, et al. Improvement of physical activity in chronic obstructive pulmonary disease by pulmonary rehabilitation and pharmacological treatment. Respiratory investigation. 2018;56(4):292-306.

2. Wiklund P. The role of physical activity and exercise in obesity and weight management: Time for critical appraisal. Journal of Sport Health Science. 2016;5(2):151-4.

3. Mañas A, et al. Dose-response association between physical activity and sedentary time categories on ageing biomarkers. BMC Geriatr. 2019;19(1):1-9.

4. Colberg SR, et al. Physical activity/exercise and diabetes: a position statement of the American Diabetes Association. Diabetes Care. 2016;39(11):2065-79.

5. Palermo A, et al. Prevention of type 2 diabetes mellitus: is it feasible? Diab/Metab Res Rev. 2014;30(S1):4-12.

6. Wu N, et al. Cardiovascular health benefits of exercise training in persons living with type 1 diabetes: a systematic review and meta-analysis. Journal of clinical medicine. 2019;8(2):253.

7. Kang D-W, et al. Effects of exercise on insulin, IGF axis, adipocytokines, and inflammatory markers in breast cancer survivors: a systematic review and meta-analysis. Cancer Epidemiology Prevention Biomarkers. 2017;26(3):355-65.

8. Kelley GA, Kelley KS, Pate RR. Effects of exercise on BMI z-score in overweight and obese children and adolescents: a systematic review with meta-analysis. BMC Pediatr. 2014;14(1):1-16.

9. Colberg SR, et al. Exercise and type 2 diabetes: the American College of Sports Medicine and the American Diabetes Association: joint position statement. Diabetes Care. 2010;33(12):e147-67.

10. Bull FC, et al. World Health Organization 2020 guidelines on physical activity and sedentary behaviour. Br J Sports Med. 2020;54(24):1451-62.

11. Razee $\mathrm{H}$, et al. Beliefs, barriers, social support, and environmental influences related to diabetes risk behaviours among women with a history of gestational diabetes. Health Promotion Journal of Australia. 2010;21(2):130-7. 
12. Rawal LB, et al., Physical activity among adults with low socioeconomic status living in industrialized countries: a metaethnographic approach to understanding socioecological complexities. Journal of environmental and public health, 2020. 2020

13. Markiewicz-Patkowska J, Jandová S. Physical activity of working age Wroclaw residents with reference to their income. Baltic Journal of Health Physical Activity. 2019;11(1):96-105.

14. Amaltinga APM. Non adherence to diabetic medication among diabetic patients, a case study of Dormaa Hospital Ghana. Science Journal of Public Health. 2017;5(2):88-97.

15. Farrar D, et al. Risk factor screening to identify women requiring oral glucose tolerance testing to diagnose gestational diabetes: a systematic review and meta-analysis and analysis of two pregnancy cohorts. PloS one. 2017;12(4):e0175288.

16. Organization WH, Global Physical Activity Questionnaire (GPAQ). Analysis Guide: World Health Organization. 2017.

17. Eva JJ, et al. Self-care and self-management among adolescent T2DM patients: a review. Front Endocrinol. 2018;9:489.

18. Morowatisharifabad MA, et al. Study on social support for exercise and its impact on the level of physical activity of patients with type 2 diabetes. Open access Macedonian journal of medical sciences. 2019;7(1):143.

19. Lindgren $\mathrm{M}$, et al. Physical activity pattern, cardiorespiratory fitness, and socioeconomic status in the SCAPIS pilot trial-a crosssectional study. Preventive medicine reports. 2016;4:44-9.

20. Moore GF, Littlecott HJ. School-and family-level socioeconomic status and health behaviors: multilevel analysis of a national survey in Wales, United Kingdom. J Sch Health. 2015;85(4):267-75.

21. Althoff T, et al. Large-scale physical activity data reveal worldwide activity inequality. Nature. 2017;547(7663):336-9.

22. Cleland CL, et al. The effectiveness of physical activity interventions in socio-economically disadvantaged communities: a systematic review. Preventive medicine. 2012;54(6):371-80.

23. Bell CN, et al. Race disparities in cardiovascular disease risk factors within socioeconomic status strata. Ann Epidemiol. 2018;28(3):147-52.

24. Hankonen $\mathrm{N}$, et al. What explains the socioeconomic status gap in activity? Educational differences in determinants of physical activity and screentime. BMC Public Health. 2017;17(1):1-15.

25. Kruk J, Czerniak U. Physical activity and its relation to cancer risk: updating the evidence. Asian Pac J Cancer Prev. 2013;14(7):3993-4003.

26. Kyu HH, et al., Physical activity and risk of breast cancer, colon cancer, diabetes, ischemic heart disease, and ischemic stroke events: systematic review and dose-response meta-analysis for the Global Burden of Disease Study 2013. bmj, 2016. 354.

27. Grize L, et al. Trend in active transportation to school among Swiss school children and its associated factors: three crosssectional surveys 1994, 2000 and 2005. International Journal of Behavioral Nutrition Physical Activity. 2010;7(1):1-8.

28. Durand $\mathrm{CP}$, et al. A systematic review of built environment factors related to physical activity and obesity risk: implications for smart growth urban planning. Obesity reviews. 2011;12(5):e173-82.

29. Fiscella NA, et al. Influence of Neighborhood Environment on Physical Activity Participation among Children with Autism Spectrum Disorder. Autism Res. 2021;14(3):560-70.

30. Andersen L, Gustat J, Becker AB. The relationship between the social environment and lifestyle-related physical activity in a lowincome African American inner-city southern neighborhood. Journal of community health. 2015;40(5):967-74.

31. Lee RE, et al. Neighborhood factors influence physical activity among African American and Hispanic or Latina women. Health Place. 2012;18(1):63-70.

32. Franzini L, et al. Influences of physical and social neighborhood environments on children's physical activity and obesity. American journal of public health. 2009;99(2):271-8.

33. Koetsenruijter $\mathrm{J}$, et al. Social support and health in diabetes patients: an observational study in six European countries in an era of austerity. PloS one. 2015;10(8):e0135079.

34. Dunbar EL, et al. Evaluating the impact of a community health worker programme on non-communicable disease, malnutrition, tuberculosis, family planning and antenatal care in Neno, Malawi: protocol for a stepped-wedge, cluster randomised controlled trial. BMJ open. 2018;8(7):e019473.

35. Laar AK, et al. Health system challenges to hypertension and related non-communicable diseases prevention and treatment: perspectives from Ghanaian stakeholders. BMC Health Serv Res. 2019;19(1):1-13.

Loading [MathJax]/jax/output/CommonHTML/jax.js

Page $11 / 12$ 
36. Letebo M, Shiferaw F. Adapting HIV patient and program monitoring tools for chronic non-communicable diseases in Ethiopia. Globalization health. 2016;12(1):1-8. 